\title{
October 2019 SAPHIRE 8 Software Quality Assurance Oversight Status Report
}

James K Knudsen, S. Ted Wood

October 2019

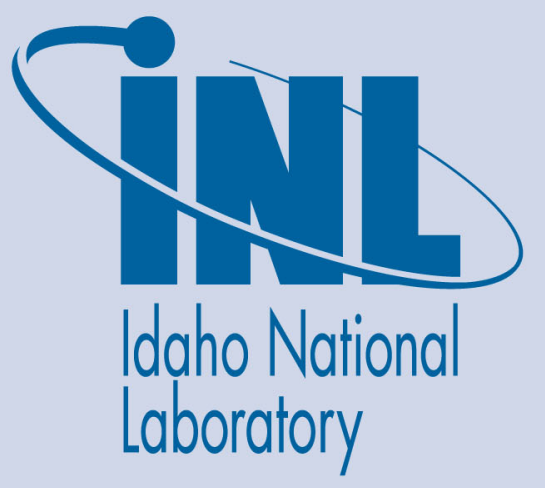

The INL is a U.S. Department of Energy National Laboratory operated by Battelle Energy Alliance 


\title{
October 2019 SAPHIRE 8 Software Quality Assurance Oversight Status Report
}

\author{
James K Knudsen, S. Ted Wood
}

October 2019

Idaho National Laboratory Idaho Falls, Idaho 83415

http://www.inl.gov

Prepared for the U.S. Department of Energy Office of Nuclear Energy Under DOE Idaho Operations Office Contract DE-AC07-05ID14517 


\section{October 2019 Software Quality Assurance Oversight Status Report}

\section{SAPHIRE 8 Quality Assurance Program Project: NRC-HQ-60-17-T-0006}

By James K Knudsen, S. Ted Wood 


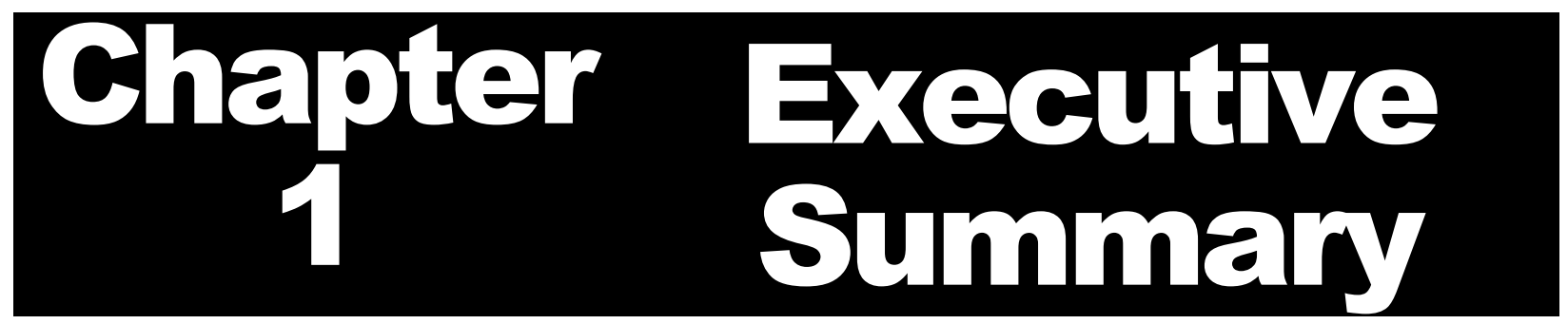

The software quality assurance oversight consists of updating and maintaining revision control of the System Analysis Program for Hands-on Integrated Reliability Evaluations (SAPHIRE) Version 8 quality assurance program documentation and of monitoring revision control of the SAPHIRE Version 8 source code. This report summarizes the oversight efforts through description of the revision control system (RCS) setup, operation and contents. Documents maintained under revision control include the Acceptance Test Plan (ATP), Configuration Management Plan, Quality Assurance Plan, Software Project Plan, Requirements Traceability Matrix (RTM), System Test Plan, Significance Determination Process (SDP) Interface Training Manual, and the SAPHIRE 8 "New Features and Capabilities Overview." These documents are referred to and can be transmitted upon request of the Nuclear Regulatory Commission (NRC) Contracting Officer's Representative (COR) and NRC Alternate (ALT) COR. 


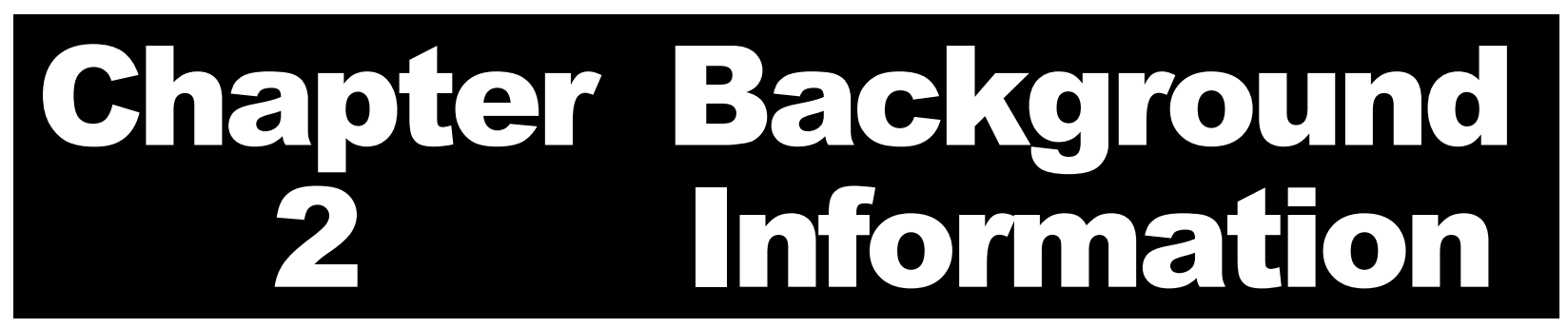

Many revision control packages have become available for software and documentation since we chose the Component Software Document Explorer when developing SAPHIRE 8. Most applications are now integrated into a complete system where the code is checked out into a built-in editor and returned. There are advantages and disadvantages to these integrated packages. The greatest advantage is the allin-one nature of the system. The greatest disadvantage is the inflexibility in design tools for the developer. For our purposes, we track many documents and not just software code modules. The current version of RCS provides the necessary capabilities at revision control and allows the developer to continue to use the editors they are familiar with. Although it is not as integrated as other industry leader's software revision control packages such as that provided by Microsoft, we choose to remain with this RCS software from Component Software. 


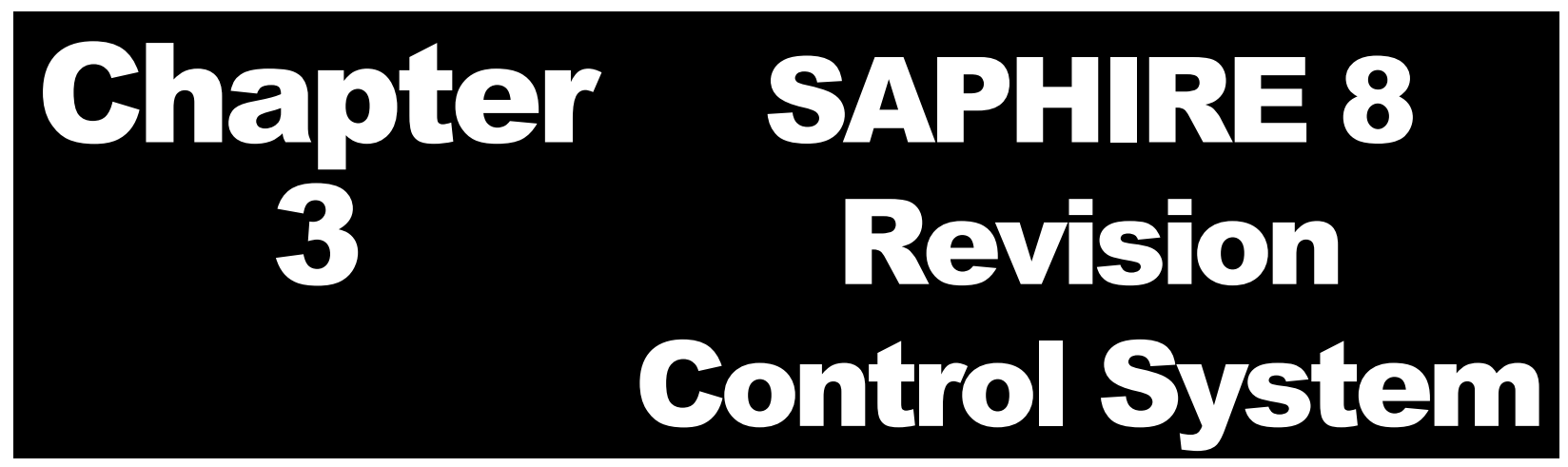

\subsection{Operation of the Revision Control System (RCS)}

SAPHIRE 8 RCS uses the Component Software Document Explorer. It is set up with the same look and feel of the Microsoft Windows Explorer with one major difference; it restricts access to revising the documents. The repository is located on a server that is backed up nightly. A local working directory is created on the user's computer (e.g., developers, Software Quality Assurance (SQA) member, managers) in which a copy is checked out to and locked from other users changing on the server. Once revisions are made, the new document is checked back in and the revision number will increase by one, such as from 1.2 to 1.3. Only the newest revisions are used for the SAPHIRE Version 8 Quality Assurance (QA) documentation and the older revisions can be viewed and used if necessary. The same applies to the software source code modules. The newest revisions are used for building the latest version of SAPHIRE Version 8, but the older ones are available for review and use if necessary. A sample view of the Software Verification and Validation Plan (SVVP) and QA documents in the repository is provided below.

\begin{tabular}{|c|c|c|c|c|c|}
\hline \multicolumn{5}{|c|}{ O CompunentSolthare Docurrent Eaploser : } & 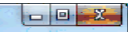 \\
\hline \multicolumn{6}{|c|}{ File Edit Kor Pruject Milestanes Woulflow Hep } \\
\hline 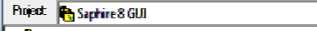 & & 7 & & & \\
\hline 日e Projet:Siphire8 GUI & - & Dlocument Name & | Type & Folds lame & \\
\hline O add-ins & & 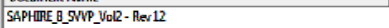 & doce & 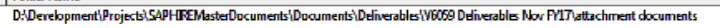 & \\
\hline \multirow{2}{*}{-Q CCrolPmoj } & & 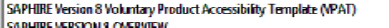 & doc & 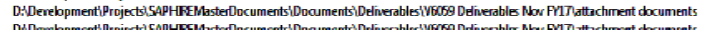 & \\
\hline & & 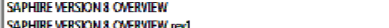 & dear & 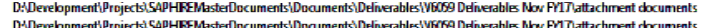 & \\
\hline 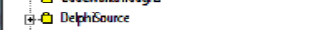 & & 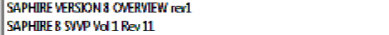 & $\begin{array}{l}\text { duck } \\
\text { decr }\end{array}$ & 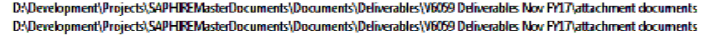 & \\
\hline D Dils & & 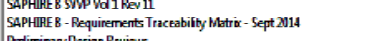 & 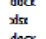 & 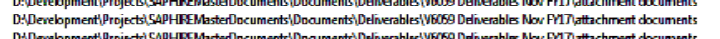 & \\
\hline $\begin{array}{l}\text { B Betestifies } \\
\text { D Buglogs }\end{array}$ & & 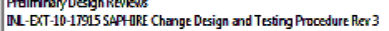 & $\begin{array}{l}d n \alpha \\
d n a x\end{array}$ & 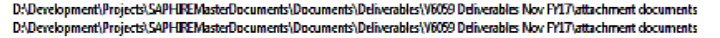 & \\
\hline B Buglogs & & 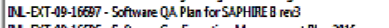 & doos & 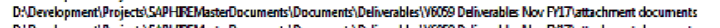 & \\
\hline O Goding Standads & & 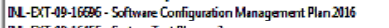 & dock & 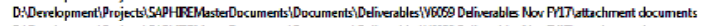 & \\
\hline 19-0 Delivarables & & [NA-ETT-19-16455- Sygten Test Planner] & doc & 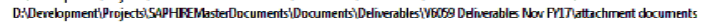 & \\
\hline \multirow{2}{*}{ 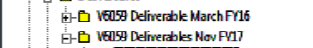 } & & 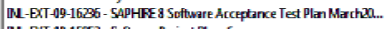 & docx & 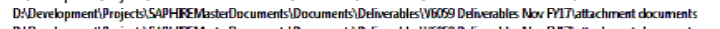 & \\
\hline & & 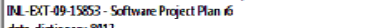 & doar & 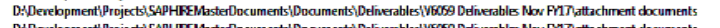 & \\
\hline 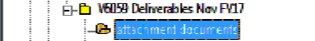 & & 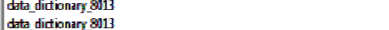 & $\begin{array}{c}\mathrm{pdi} \\
\mathrm{hbml}\end{array}$ & 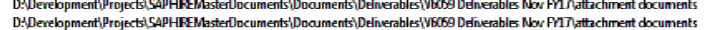 & \\
\hline PQ Ner SAPHFE RAResses & & Citkiad Design Reriews & & 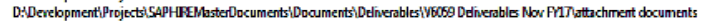 & \\
\hline $\begin{array}{l}\text { - G SMRR-Support } \\
\text { - S Soredshett information }\end{array}$ & & & & & \\
\hline F Design Documrents & & & & & \\
\hline \multicolumn{4}{|l|}{ For Help, press F1 } & & CSP $\mid \mathbf{N J M}$ \\
\hline
\end{tabular}




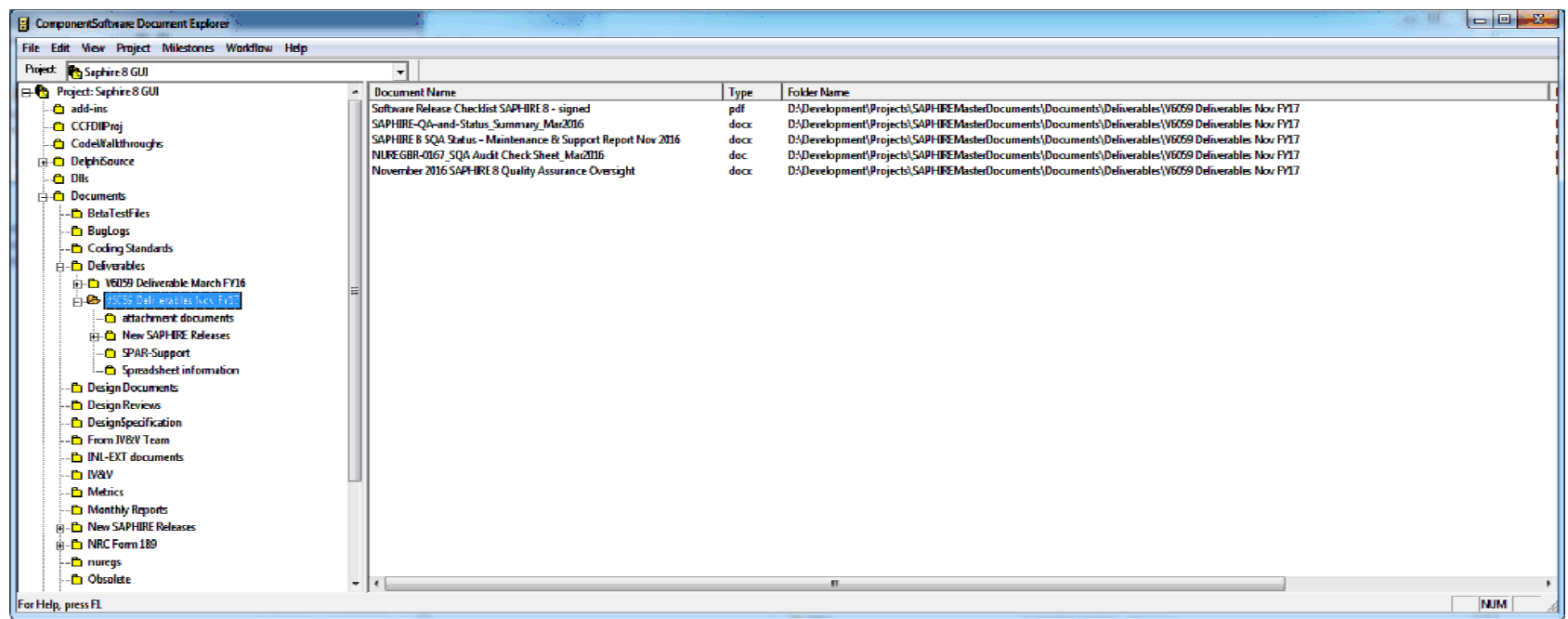

\subsection{Contents of the Revision Control System}

The RCS contains the Modula-2 and Delphi source codes that are used in the development of SAPHIRE Version 8 . The RCS also contains design and quality assurance documentation. A list of the modules and documents controlled is provided below.

\begin{tabular}{|l|l|}
\hline Directory & $\begin{array}{l}\text { Content Descriptions } \\
\text { add-ins }\end{array}$ \\
\hline CCFDe.
\end{tabular}




\begin{tabular}{|c|c|}
\hline & $\begin{array}{l}\text { documents as part of the living document system developed in } \\
\text { fiscal year (FY)-11. }\end{array}$ \\
\hline Documents/DesignSpecification & $\begin{array}{l}\text { Design Documents of major changes that are tracked in the } \\
\text { Requirements Traceability Matrix. }\end{array}$ \\
\hline Documents/From IV\&V Team & IV\&V reports from the initial SAPHIRE 8 release. \\
\hline Documents/INL-EXT documents & $\begin{array}{l}\text { Quality Assurance documents passed through the INL'S } \\
\text { Scientific and Technical Information Management System for } \\
\text { external release. } \\
\text { These include most plans except the SV\&V. }\end{array}$ \\
\hline Documents/IV\&V & The initial SAPHIRE 8 development IV\&V final reports. \\
\hline Documents/Monthly Reports & Monthly reports throughout early SAPHIRE 8 development. \\
\hline Documents/NRC Form 189 & Form 189s relating to SAPHIRE. \\
\hline Documents/NRC IAA Task 6 QA & Contracting Documents relating to SAPHIRE QA \\
\hline $\begin{array}{l}\text { Documents/NRC IAA Task } 7 \text { SAPHIRE } \\
\text { Enhance }\end{array}$ & $\begin{array}{l}\text { Contracting Documents relating to SAPHIRE Algorithm } \\
\text { Enhancements }\end{array}$ \\
\hline Documents/NUREGs & NUREGs relating to SAPHIRE Version 8. \\
\hline Documents/Obsolete & $\begin{array}{l}\text { Collection of obsolete quality assurance documents not a } \\
\text { part of an official document or revision of one. Basically, this } \\
\text { is a junk drawer where a rejected idea may come up again } \\
\text { and this would save time. }\end{array}$ \\
\hline Documents/SVVP and QA & $\begin{array}{l}\text { Contains SVVP volumes } 1 \text { and 2, and Requirements } \\
\text { Traceability Matrices. }\end{array}$ \\
\hline Documents/Training & Basics and Advanced Manuals, workshops and SDP training. \\
\hline Documents/User Documentation & Old NUREGs, SAPHIRE 8 Overview. \\
\hline Documents/V\&VFY07 & SAPHIRE Version $7 \mathrm{~V} \& \mathrm{~V}$. \\
\hline Graphics & Graphic files used in SAPHIRE 8. \\
\hline Help & Users Guide. \\
\hline Publish & $\begin{array}{l}\text { Sample developed reports output with sub-directories for } \\
\text { more graphics, icons, scripts and styles relating to reports. }\end{array}$ \\
\hline Saf7b31 & $\begin{array}{l}\text { The Modula-2 source modules that are the majority of the } \\
\text { SAPHIRE Version } 8 \text { Application Programming Interface (API). } \\
\text { Their file extension that ends in .def or .mod such as } \\
\text { solvelib.def and solvelib.mod. }\end{array}$ \\
\hline
\end{tabular}




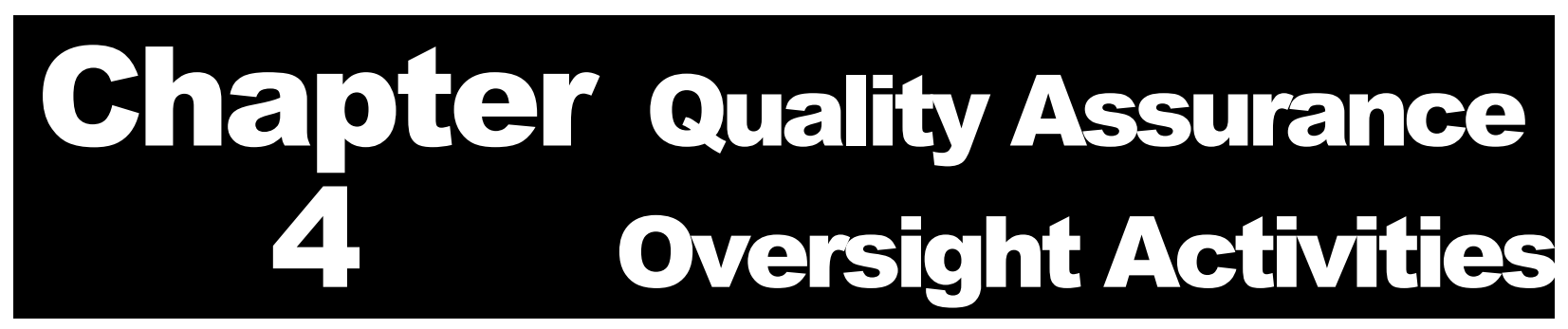

The SQA creates and maintains the quality assurance documentation in the RCS as new documents are created, such as the Preliminary Design Review and Critical Design Review documents or when there is a new revision of the quality assurance documents warranted by procedure or design changes. The following are some of the documents that were reviewed and updated as necessary up to October 2019:

- Acceptance Test Plan

- Configuration Management Plan

- QA Plan

- Project Plan

- RTM

- SAPHIRE Version 8 Software Verification and Validation Plan

The RTM has been updated to identify the latest features that have been added to SAPHIRE. Due to the updates in the RTM, the "SAPHIRE Version 8 Software Verification and Validation Plan Volume 2 (SV\&V Volume 2)" has been updated to match the information added. The updated RTM and SV\&V-Volume II have been placed in the RCS.

These documents can be provided upon request. 


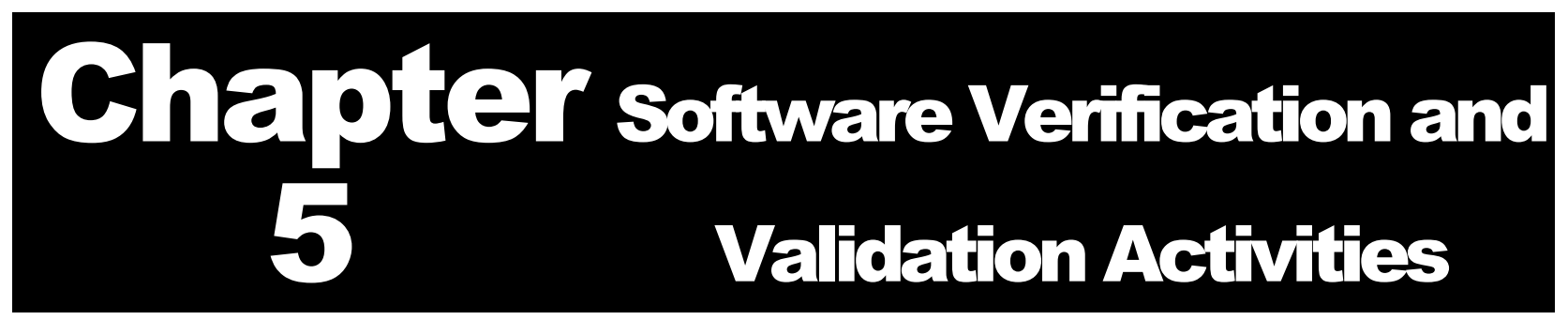

Activities on the current software verification and validation (SV\&V) Volume 1 and 2 will be discussed below. This section documents the activities performed in relationship to the SV\&V plan between June 2019 and October 2019. The SV\&V Volume 1 and/or Volume 2 can be provided upon request.

\subsection{SV\&V Updates through October 2019}

The SV\&V reports were officially updated and released in September 2012. During the period between June 2019 and October 2019, the SV\&V Volume 2 was updated to match the work performed on the RTM. The updated version of the SV\&V Volume 2 has been placed into the RCS for document control.

The RTM update was completed during this period to match new features that have been added to the latest version of SAPHIRE, which is Version 8.2.0. The RTM update required the verification of the new features and the tests that are used to ensure these new features work properly. The update of the RTM also required the update of the SV\&V Volume 2 document. The update to the SV\&V Volume 2 was necessary to document the cross-referencing between the SV\&V Volume 2 information and the tests required to verify the features that have been added to SAPHIRE. This verification ensures the tests are implemented and working correctly. The new features and previously added features will have either an automated or a manual test in order to verify they work as requested and developed.

\subsection{SV8.V Peer Review and Improvements}

The SVVP structure lends itself to the addition of new design features, tests, and coding standards. Maintenance of the document keeps it both relevant and useful as a reference for the latest state of the SAPHIRE project's verification and validation actions and as a record of prior actions. Its current structure is a result of the independent verification and validation (IV\&V) team input and review. No major changes to the SVVP layout were considered necessary at this time. The structure; however, provides for a living process as to promote the continual update of the different documents on an as needed basis in order to stay synchronized with the new features being added SAPHIRE.

Peer review concentrated on the verification and review of the bug issues, lessons learned going forward, and review of the identified issues that have been reported since the latest release of SAPHIRE Version 8.2.0. This process helps prioritize the issues that need to be fixed based on their potential impacts on performing the different required analyses.

Figure 1 shows an incident plot through October 2019 of the identified issues from the SAPHIRE website. 
The plot is comprised of identified user interface bugs and calculation bugs from version 8.0.8 through version 8.2.0. There are seven different labels used to identify the status of the identified issue. These seven labels are:

1) resolved [issue has been fixed and will be in the next release]

2) awaiting review [issue documented on the SAPHIRE website, but currently has not been addressed]

3) in review [issue is being evaluated to verify the issue in order to fix it]

4) underway [issue is currently being worked on and will be fixed for the next release]

5) documenting [issue has been resolved and needs to be verified in the pre-release of SAPHIRE]

6) Tabled [issue cannot be repeated when tested or if a new feature will not be added to the next released version of SAPHIRE or may not be added]

7) Not Implemented [new feature will not be implemented into SAPHIRE due to different factors (e.g., complexity, very small improvement versus cost)]

The items are grouped together and noted as either being closed (resolved; tabled or not implemented), those that are still open (awaiting review, in review, underway or documenting. There are 12 issues identified as open out of the 164 issues listed on the SAPHIRE website. Of the 12 open issues, 9 are awaiting review and 3 are in review. The 9 awaiting review are related to Version 8.2.0 and once Version 8.2.1 is released these issues will be fixed and closed. The remaining 3 open issues are from version 8.1.8 and still need to be addressed. These 3 issues will be addressed and either fixed in the next release of SAPHIRE (version 8.2.1) provided the identified issues can be replicated or Tabled if through careful scrutiny cannot be replicated in Version 8.2.1 of SAPHIRE.

\section{SAPHIRE 8 Incidents (Calculation/User Issues) Open/Closed Status between \\ July 2012 and October 2019 (Version 8.0.8 to present)}

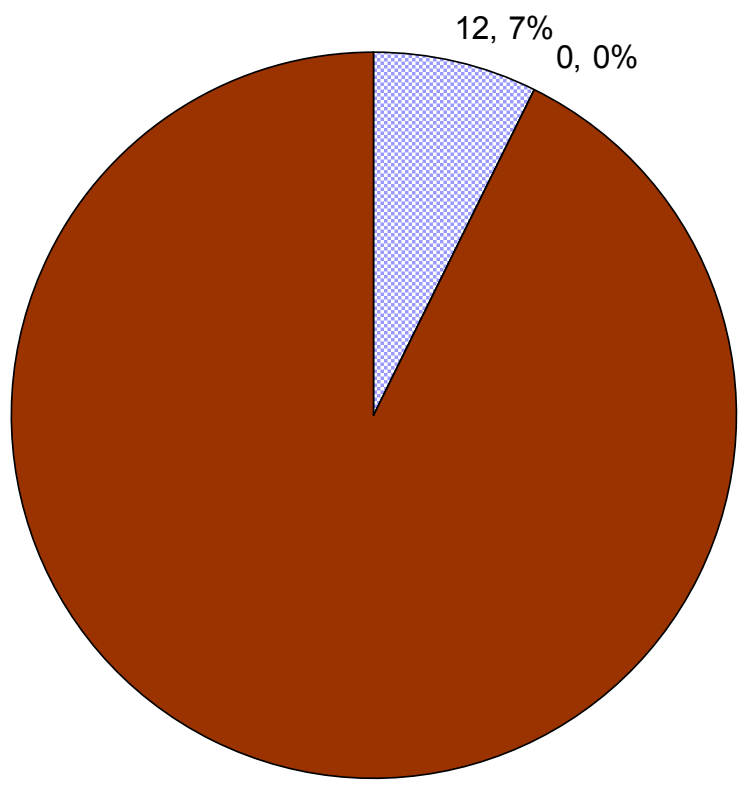

圆Open

Requires

Verification

$\square$ Closed

$152,93 \%$ 
Figure 1. SAPHIRE 8 Open/Closed Incidents of Calculation or User Interface Bugs

Figure 2 shows a detailed breakdown of the bug and user interface issues identified through October 2019. This plot identifies the number of issues that have been resolved, not implemented, in review, awaiting review, documenting and tabled. There are 164 calculation or user interface issues that are being tracked from SAPHIRE Version 8.0.8 to SAPHIRE Version 8.2.0.

\section{SAPHIRE Incidents (Calculation/User Issues) Status between July 2012 and October 2019 Version 8.0.8 to present)}

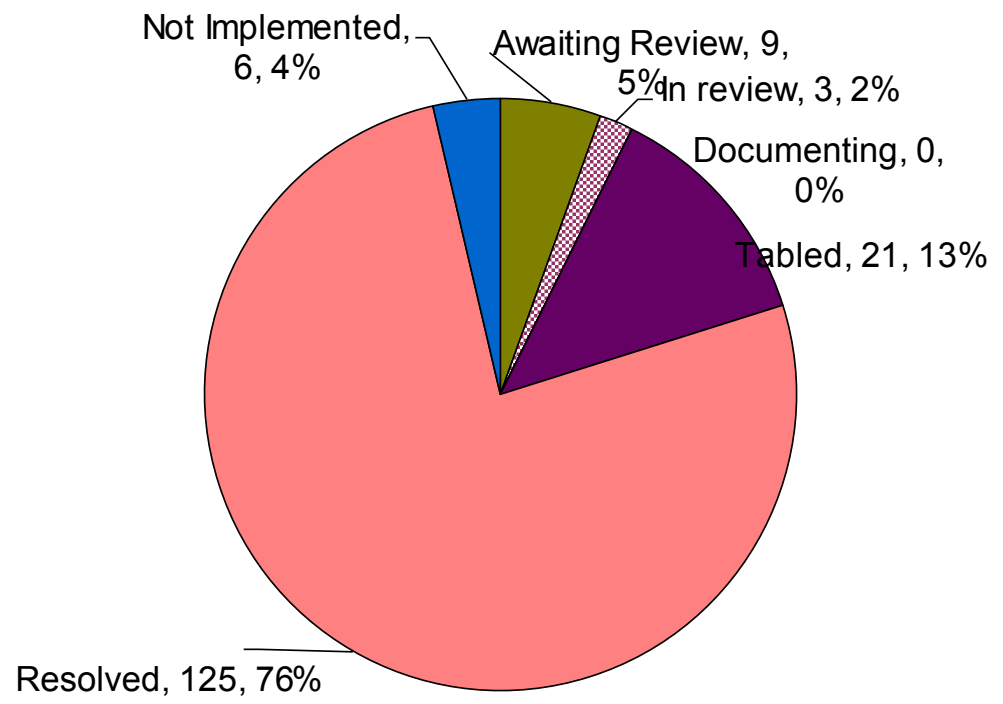

Figure 2. SAPHIRE 8 Incident Status Breakdown of Calculation or User Interface Bugs

The information provided in Figure 2 is comprised of the different categories and the following will provide a breakdown the different categories to give a better picture of the status of outstanding issues. Of the 164 identified calculation or user interface bug issues, 117 are calculation bugs and 47 are identified as user interface issues. The 117 identified calculation bug issues are categorized as 94 having been resolved, 15 tabled or not implemented because of older version issues and the remaining 8 issues are still under review, awaiting review or documenting. The calculation bug issues identified as awaiting review are from SAPHIRE Version 8.2.0 and once the next version (8.2.1) is released these issues will be verified and completed. The 47 identified user interface issues are categorized as 31 having been resolved, 12 tabled or not implemented and the remaining 4 still under review or awaiting review. The user interface bug issues identified as awaiting review are from Version 8.2.0 and once the next version of SAPHIRE is released these issues will be verified and completed. 
Figure 3 shows an incident plot through October 2019 of the identified new features or suggested improvements from the SAPHIRE website. This plot is comprised of just new features and suggested improvements from version 8.0.8 through version 8.2.0. The items are grouped together and noted as either being closed (resolved, tabled or not implemented), those that are still open and need to be resolved (awaiting review, in review, underway or documenting). A total of 55 new features or suggested improvements are identified as open out of the 129 identified. Of the 129 identified new features or suggested improvements, 1 is awaiting review, 73 are closed and 55 are still open. The open items are being discussed with the programmer to develop a priority list. The priority list of new features and suggested improvements will be discussed with NRC ALT COR for inclusion into SAPHIRE.

\section{SAPHIRE 8 Suggested Improvements Open/Closed Status July 2012 and October 2019 (Version 8.0.8 to present)}

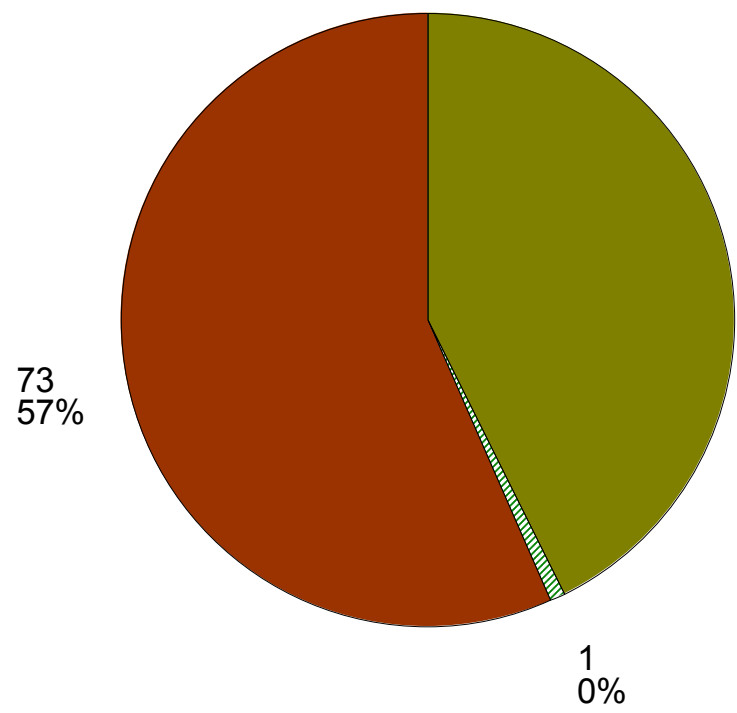

55

$43 \%$

Open

Requires Verification

Closed

Figure 3. SAPHIRE 8 Open/Closed Incidents of Suggested Improvements and New Features

Figure 4 shows a detailed breakdown of the new features and suggested improvements through October 2019. This plot identifies the number of features that have been resolved, not implemented, in review, awaiting review, documenting and tabled. There are 129 identified new features or suggested improvements that are being tracked from SAPHIRE Version 8.0.8 to SAPHIRE Version 8.2.0.

The information provided in Figure 4 is comprised of different categories of inputs and the following will provide a breakdown the different categories to give a better picture of the status of these features. Of the 129 identified new features or suggested improvements, 112 are suggested improvements and 15 
are identified as new features. Of the 112 suggested improvements identified, 29 have been added to resolved, 31 have been tabled or not implemented because of older version issues. The remaining 54 are still under review, awaiting review or being documented. Of the 15 new features, 7 have been resolved and added to SAPHIRE, 6 have been tabled or not implemented. The remaining 2 issues are still under review or awaiting review.

\section{SAPHIRE Suggested Improvements Status between July 2012 and October 2019 Version 8.0.8 to present)}

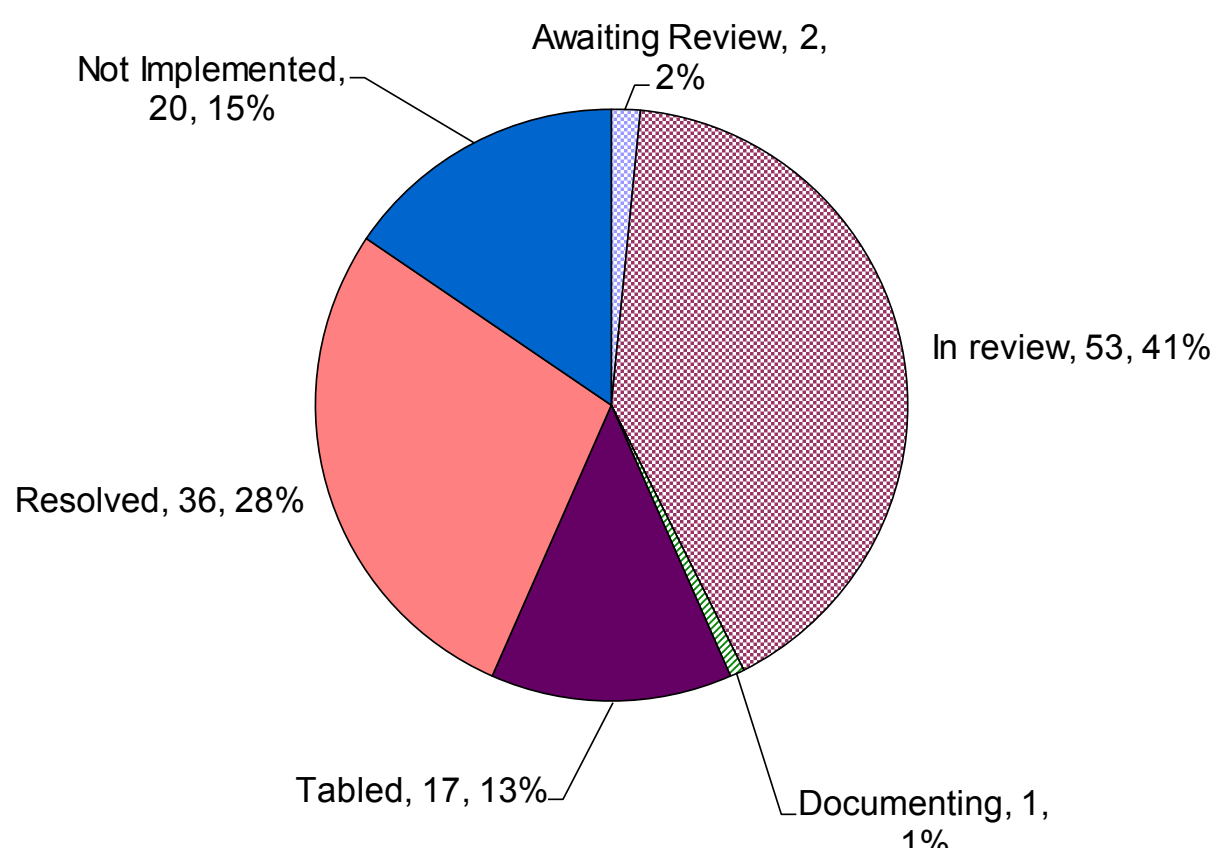

$1 \%$

Figure 4. SAPHIRE 8 Incident Status Breakdown of Suggested Improvements and New Features

Periodic peer reviews have been performed to cover design specifications, software issues and code reviews. The reviews with the SAPHIRE programmers to discuss the identified issues that were found from internal and external peer reviews and additional requirements help set priorities on what features are required to be implemented into SAPHIRE.

During the next period between November 2019 and February 2020, focus will be spent on prioritizing the suggested improvements and new features to implement them into SAPHIRE or table these because SAPHIRE has moved into a new direction. Some of these issues from older versions of SAPHIRE are still relevant to the latest version and need to be implemented if given the direction from the NRC ALT COR. A priority list has been developed to guide the work to be performed during FY-20. Also, the review of the identified issues will help guide when SAPHIRE Version 8.2.1 will be released.

The Excel spreadsheet used to develop the plots in Figures 1, 2, 3 and 4 can be provided to the NRC COR 
and/or NRC ALT COR upon request.

\subsection{INL SAPHIRE 8 Quality Assurance Review}

During the period between June 2019 and October 2019, the quality assurance documents were reviewed. No issues were identified and therefore no updates were performed to these documents except for the RTM and SV\&V Volume 2. The RTM was updated to bring it into concurrence with the latest version of SAPHIRE 8.2.0. During the updating of the RTM, the SV\&V Volume 2 was also updated to incorporate the RTM changes.

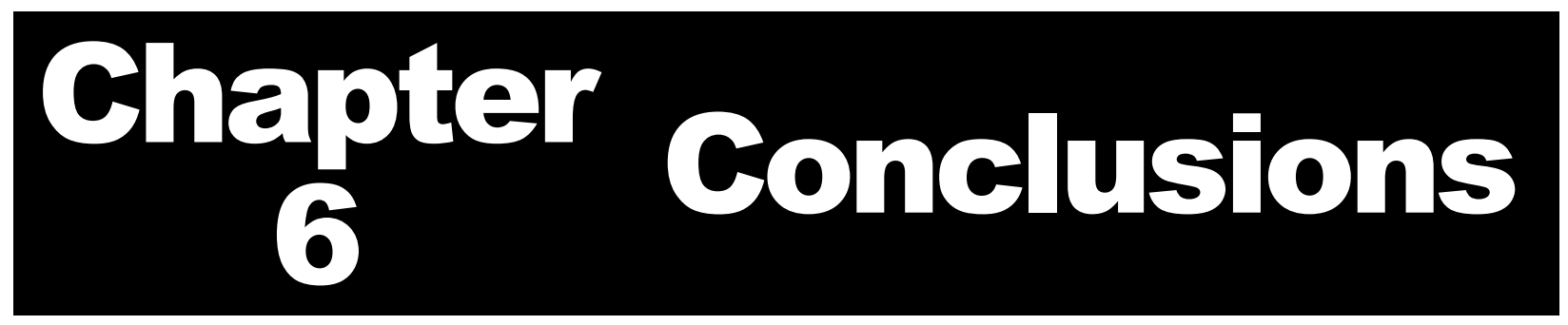

SAPHIRE 8 Quality Assurance oversight is greatly facilitated by the RCS program. The maintenance of this filing and repository system keeps the SAPHIRE Version 8 software program running smoothly and provides a history and point of use fallback for both code modules and quality assurance documentation if necessary. The SQA oversight activities maintain this RCS through monitoring its use as a code repository and organizing its use as a document repository.

The monitoring and updating of the identified issues on the SAPHIRE website enhances the software. This process needs to be continued and focus on resolving outstanding issues by verifying they have been fixed or no longer part of the pathway that SAPHIRE has taken. The remaining issues need to be assessed to determine their final resolution, i.e., tabled or not implemented based upon the current software capability and/or direction from the NRC COR or NRC ALT COR. 